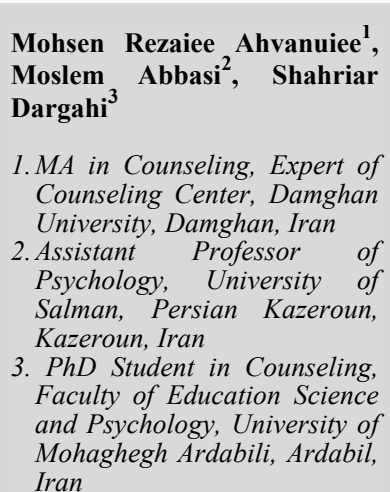

Corresponding Author: MA in Counseling, Expert of Counseling Center, Damghan University, Damghan, Iran

Tel: 0919- 1316706

E-mail: Mohsenrezaiee.ir69@yahoo.com

\section{The Role of Work-Family Conflict and Job Stress in the Prediction of Job Engagement of Nurses}

Received:15 Nov. 2016 ; Accepted:11 Dec. 2017

\section{Abstract}

Background and Aims: Due to the great importance that the nurses health and job engagement have in the health of their, colleagues and patients, this study Aim was investigated the role of work-family conflict and job stress in the prediction of job engagement of GACHSARAN city nurses.

Methods: The design of this study is descriptive and correlation crosses sectional design. The study population were included all male and female nurses working in hospitals and clinics in the GACHSARAN city. To select a sample of cluster sampling method was used that a total 100 nurses were selected. To collect information from the Carlson, Kakmar and Williams work - family conflict, questionnaire (2000), work engagement questionnaire and French et al nursing stress scale revised (2000) was used.

Results: The results showed that there is a significant negative correlation between job stress with Job engagement, enthusiasm and charisma at work $(p<0.01)$ and dedicated to the task $(p<0.05)$. Also, there is a significant negative correlation between the workfamily conflict with Job engagement and all its dimensions $(p<0.01)$. In addition, this study showed that the Predictor variables the job stress and work-family conflict are able to account for 29.4 percent of the nurses job engagement.

Conclusion: In general, considering that the interaction between family and work issues and job stress is predictors of job engagement of nurses, with education about managing and improving the nurse's quality of their marital and family life and with training the stress management can be to improve their job engagement.

Keywords: Work-family conflict, Job stress, Job engagement, Nurses 


\section{نقش تعارض كار - خانواده و استرس شغلى در بيشبينى اشتياق شغلى يرستاران}

تاريخ دريافت مقاله: 9ه/N/TQ؛ تاريخ بذيرش: •99/9/T

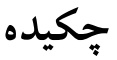

زمينه و هدف: با توجه به اهميت بسيار زيادى كه سلامتى و اشتياق به كار برستاران در سلامت زندگى خـود، همكـاران و

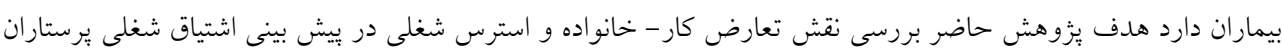

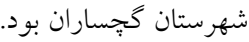

روش: طرح اين يُزوهش، طرح مقطعى - توصيفى از نوع همبستخى است. جامعه مورد مطالعه در اين يُزوهش شـامل تمـام

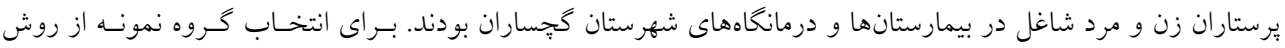

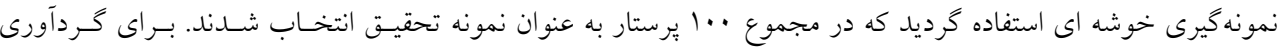

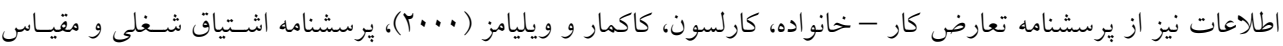
تجديدنظر شده استرس يرستارى فرنج و همكاران (F.... (T) استفاده شد.

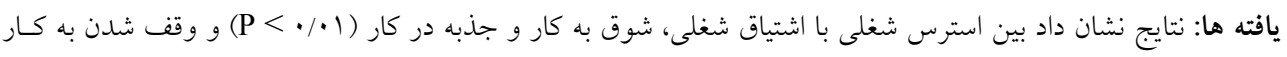

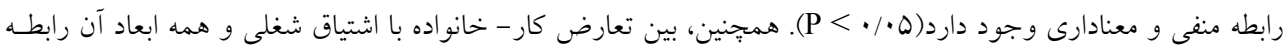

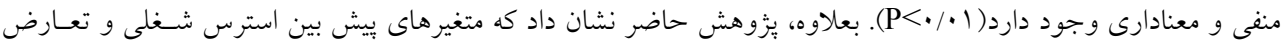

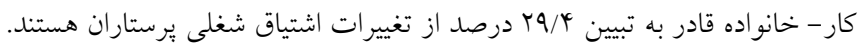
نتيجه گيرى: بطور كلى، با توجه به اينكه تعامل متقابل ميان مسائل خانواده و كار و همجنين استرس شغلى ييش بينى كننده

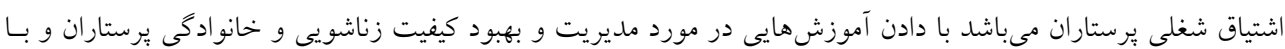

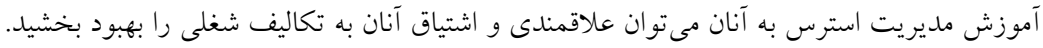
كلمات كليدى: تعارض كار - خانو اده، استرس شغلى، اشتياق شغلى، برستاران

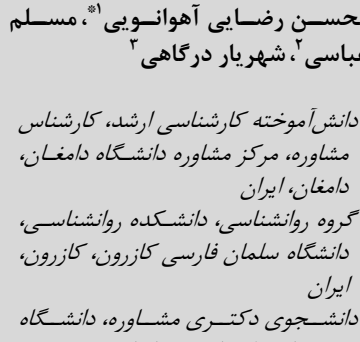

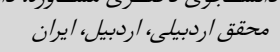




$$
\text { بررسى است. •اولا }
$$

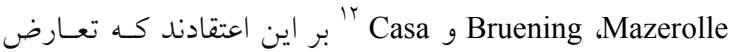

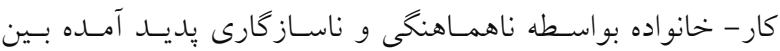
تقاضاهاى كارى با تقاضاهاى خانواده يـا زنـدكى خـانو ادكى ايجــاد

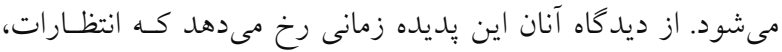

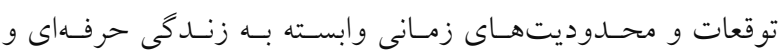
شخصى يكى فرد با هم ساز كارى نداشته باشد كـه در ايسن صـورت اداره كردن اين دو سخت و دشوار مىشود. تعارض كـار - خـانواده منجر به بيامدهاى سـازمانى بسـيارى از جملـه ناخشـنودى شـغلى، عملكرد بايين، كاهش تعهل سازمانى، حضور نامنظم در كار و ميزان

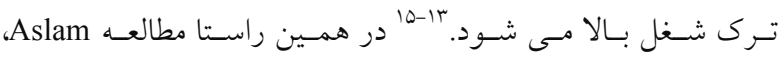
Azhar ، Shumaila كار - خانو اده و تعارض خانو اده- كـار بــا قصـــ تــــ شــل نشـان

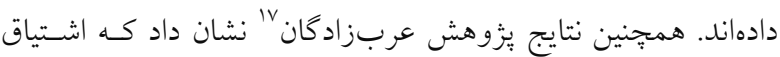
شغلى بــا تعـارض كـار - خـانواده، سـلامت، حمايـت سريرسـت و و

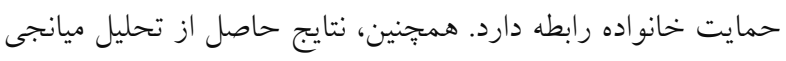

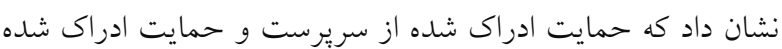
از خانو اده هر دو ميانجى گر رابطهى اشتياق شغلى با تعـارض كـار خانواده و ميانجى رابطه رابطه اشتياق شغلى با سلامت مى باشند. تعارض كار - خانواده از نوع تعارض بين نقشى است كـه بـين خواستهاى نقش كارى و خانوادكى فرد ايجاد تعارض كرده اسـت

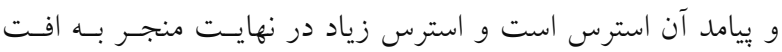

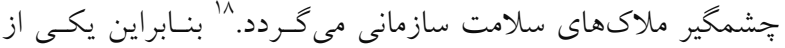

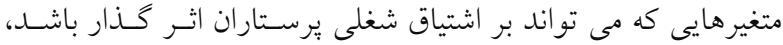
استرس شغلى است. تنيدكى يا استرس جزء شناخته شده و لاينفكى

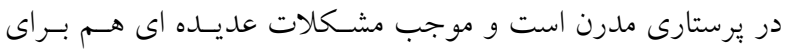

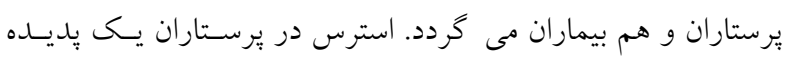

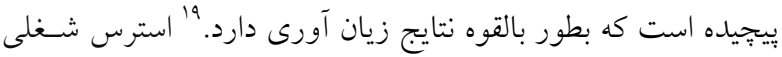
شرايطى است كه در هم ريزنده تركيبى از عواملى است كه يرستاران با آن مواجه هستند. اين عوامل عبارتند از: تعادل جسمى، روانسى يـا

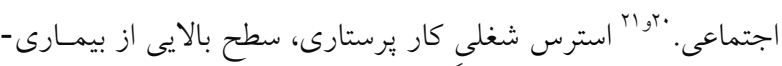

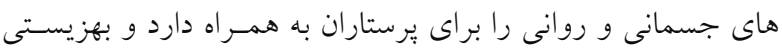

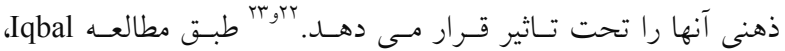

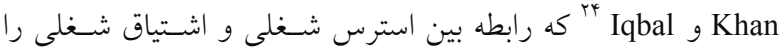

مقدمه

در كشور ما •م درصـد شـاغلين سيسـتم بهداشـت و درمـان را يرستاران تشكيل مى دهند. همجنين در اين سيستم •N درصد كارها بر

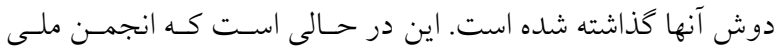
ايمنى و بهداشت حرفهاى آمريكا، برستارى را در رأس •ب حرفه بـا شيوع بالاى بيمارىهاى مربوط به استرس معرفى كرده و عقيـده بـر

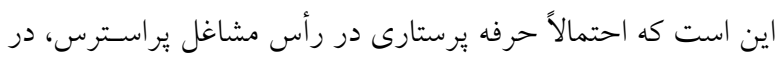

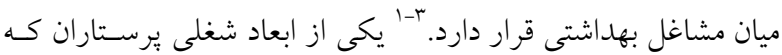
توجه به آن هم در راستاى سلامت خود يِرستاران و هم در راسـتاى افزايش توجه و علاقه يرستاران به سلامت همكاران و بيمـارانشـان داراى اهميت زيادى است، ميـزان اشـتياق شـغلى يرسـتاران اسـت. Schaufeli

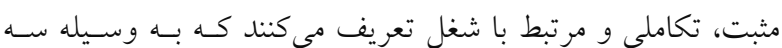
مولفه نيرومندى، فداكارى كردن و جذب شدن مشخص مىشود. در واقع، اشتياق شغلى به عنوان يك يديـانده مثبـت در محـيط كـارى و نبود ييامد منفى مانند فرسودگى شغلى، خطا و خرابكارى در شغل و

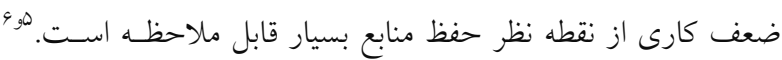

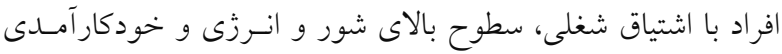
نسبت به كارشان دارند كه بر حوادثى كه زندگى آنها را تحت تاثير

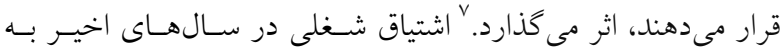

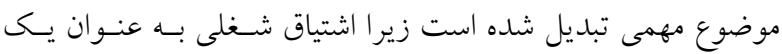

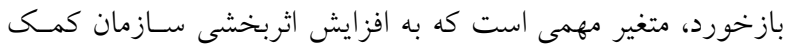

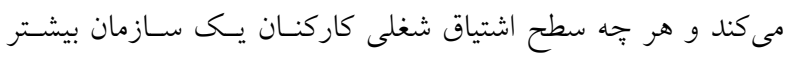
باشد اثربخشى آن سازمان نيز افزايش خواهد يافت. ^از سوى ديخـر

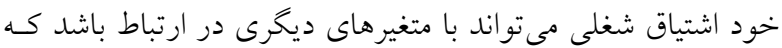

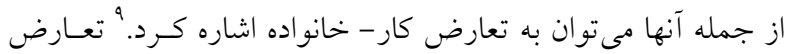
كار - خانو اده (و خانو اده- كار) مفهومى مهم در مورد رابطه و فر آيند زندگى خانوادگى و شغلى فرد است كه با مواردى مانند محيط كـار (عجين بودن با كار، ساعات كارى، حمايت كـارى، انعطـاف يـذيرى ساعات كارى و استرس ناشى از شغل) و متغيرهاى محيط غيركارى (عجين بودن با خانواده، ساعات غير كـارى، حمايتهـاى خـانوادكى،

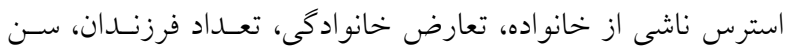

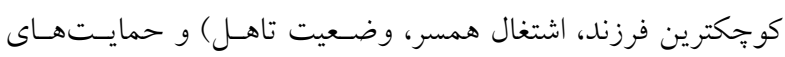

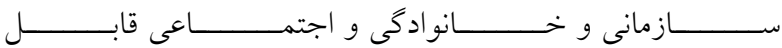




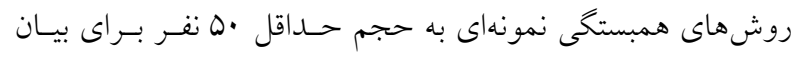

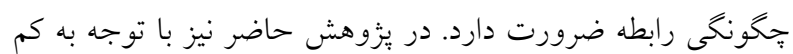

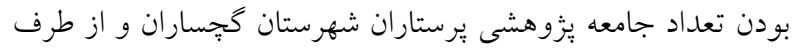

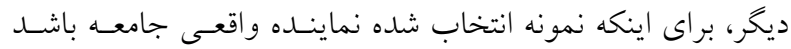

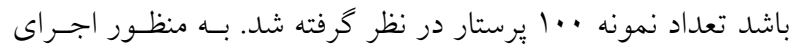
تحقيق حاضر، بعد از اخذ مجوزهاى لازم، تعهدات اخلاقى و كارى

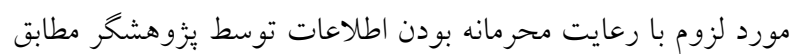
قوانين، آيين نامهها و شرايط لازم داده شد و سـرانجام بعـــ از انجـام

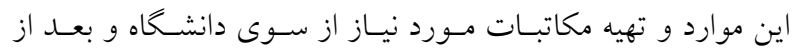
هماهنكى و كسب مجوز از مراكـز مربوطه، بـا رعايـت ملاحظـات

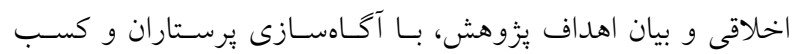

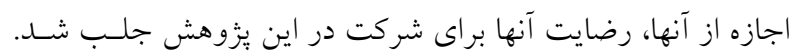

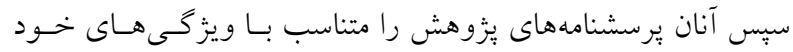
تكميل نمودند. براين اساس از ابزارهاى زير براى سنجش متغيرهاى

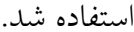
يرسشنامه اشتياق كارى: اين برسشنامه داراى \ل سـوال بـوده و

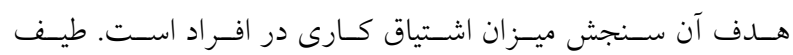

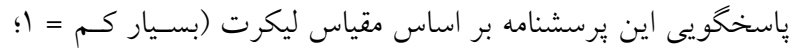

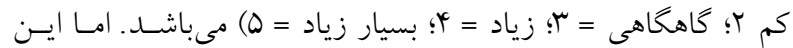

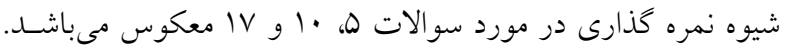

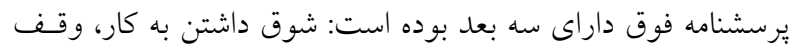

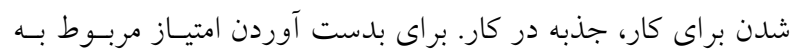

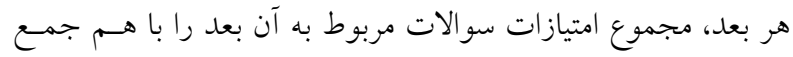
نماييد. براى بدست آوردن امتياز كلى برسشنامه، مجمـوع امتيـازات

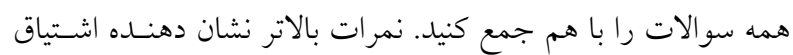

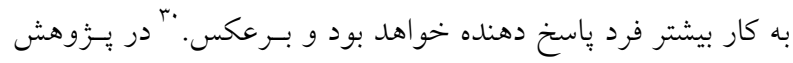

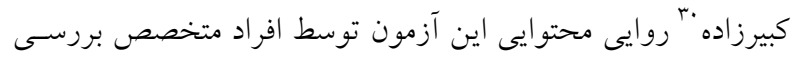
و مورد تأييد قرار كرفت. همجنين بِايائى يُرسشنامه يا قابليت اعتماد

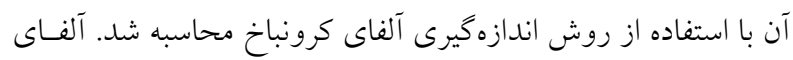

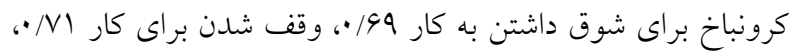
جذبه در كار 190/ مىباشد. يرسشنامه تعارض كار - خانواده: يرسشنامه ل1 إمـادهاى سـنجه

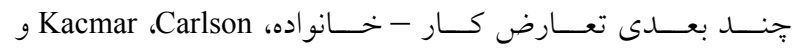
Williams بُ براى سنجش ميزان شدت تعارض كار خانواده اسـت.
بررسى نمودند بين متغيرهاى يزوهش همبستخى منفى به دست آمد،

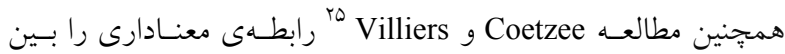
منابع استرس شغلى و سطوح اشتياق شغلى نشان داد. طبق يزوهشى

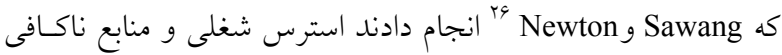
شغلى بر ميزان اشتياق شغلى تاثير دارد و براى محسـدود كردن ايسن اثرات زيانبار بايد فضاى كارى مناسبى طراحى شود.

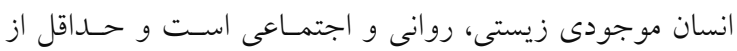

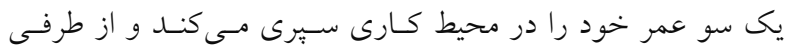

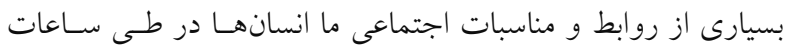

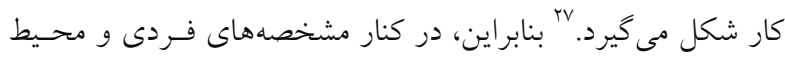

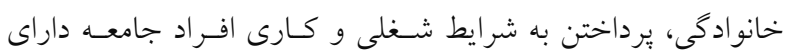

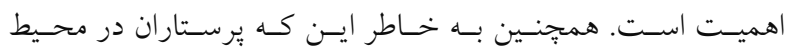

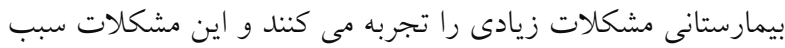
واكنش هاى عاطفى و افزايش تنش روانى مى شود و همجنسين ايسن

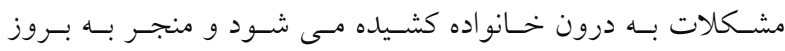

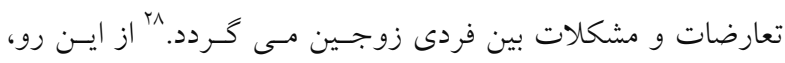

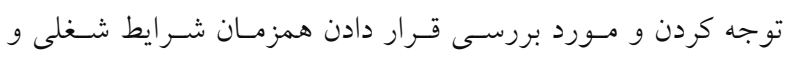

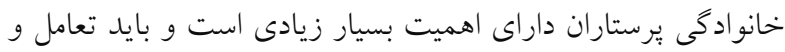
ارتباط اين شرايط مشكلزاى خـانوادگى و شـغلى (تعـارض كـار -

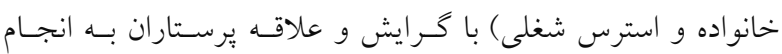

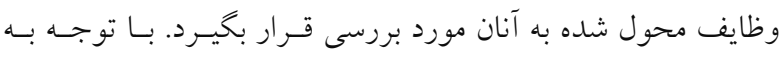

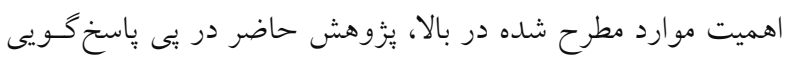

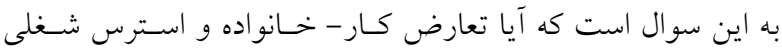
مى تواند بيشبينى كننده اشتياق شغلى برستاران باشند؟

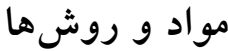

يزّوهش حاضر توصيفى از نوع همبستخى مىباشد. جامعه مورد

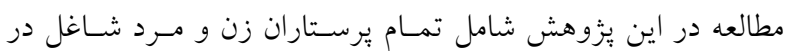
بيمارستانها و درمانگاههاى شهرستان كُجساران بودند. براى انتخاب

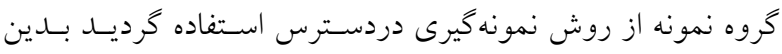

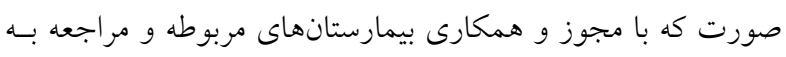

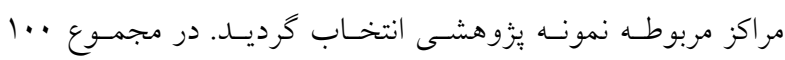
يرستار به عنوان نمونه تحقيق انتخاب شدند. در مورد انتخـاب ل.

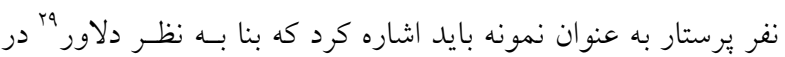


همسانى درونى آزمودن از روش آلفاى كرونباخ استفاده شـــه اسـت.

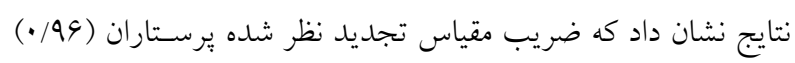

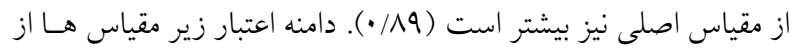

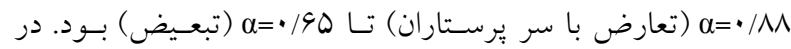

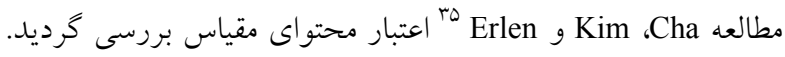
اعتبار ابزار فوق توسط 19 نفر از استادان صاحب نظـر در دانشكلده

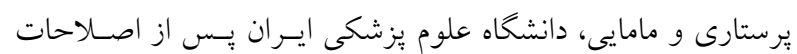

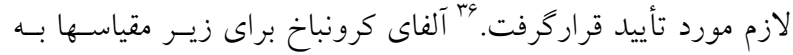

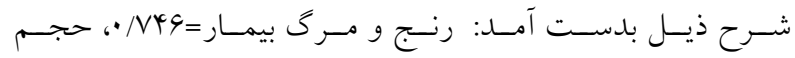

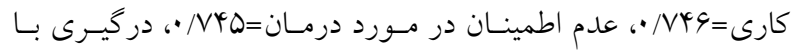

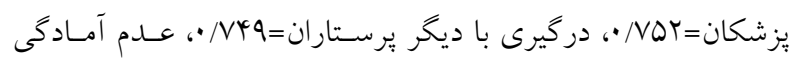

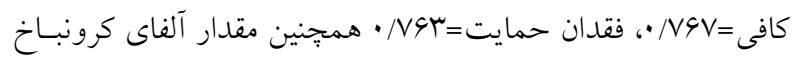

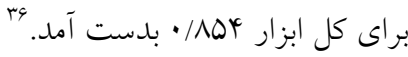

\section{يافته ها}

براساس اطلاعات جمعيت شناختى حاصـل از اعضـاى نمونسه،

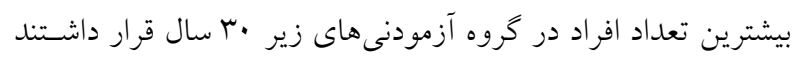

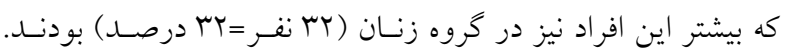

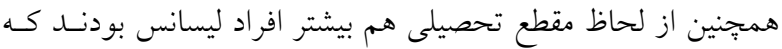

بيشتر اين افراد نيز در كروه مردان مى باشد( الثا درصد= الب نفر ).

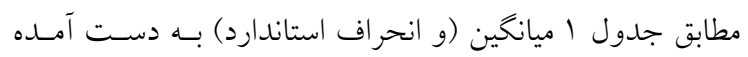

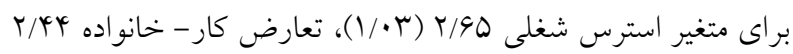

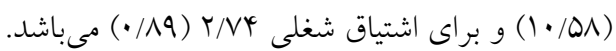

اين مقياس ابعاد شش كانه تعارض كار - خانواده را مـورد ارزيـابى

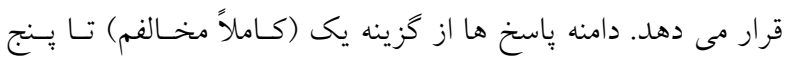

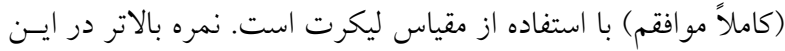

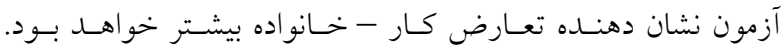

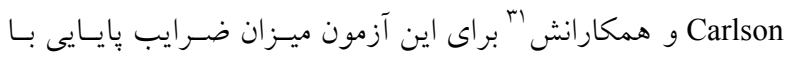

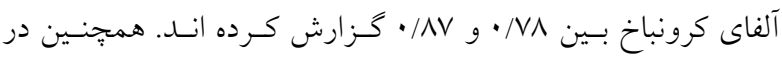

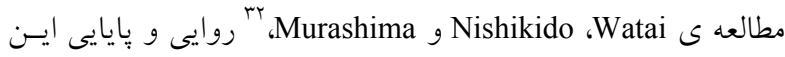

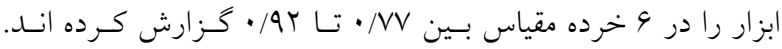

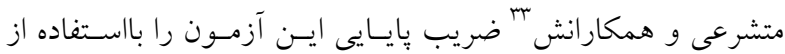

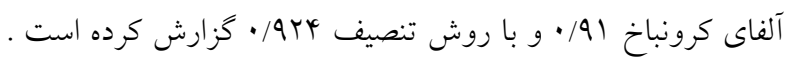

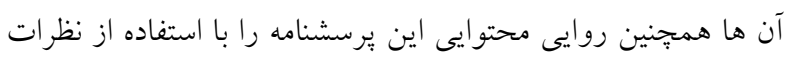

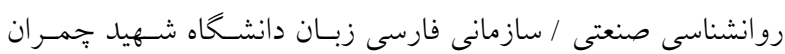
مورد تأييد قرار دادهاند. مقياس تجديدنظر شده استرس برستارى French و همكـاران (ENSS) (هدف اين برسشنامه سنجش استرس شغل برستارى است. مقياس (ENSS) نسخه تجديد نظر شــه مقيـاس اسـترس برستارى

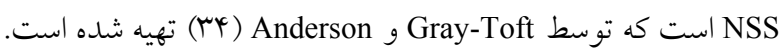
نخستين ابزارى است كه به منظور اندازهگيرى استرس يرستارى NSS

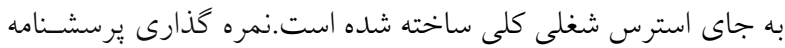

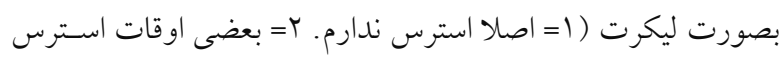
دارم. r= اغلب اوقات استرس دارم. ؟ = شديدا استرس دارم. ه= اين

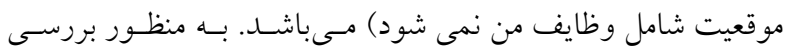

جدول ا: ميانكَين و انحراف استاندارد استرس شغلى، تعارض كار - خانواده و اشتياق شغلى (و ابعاد آن)

\begin{tabular}{|c|c|c|c|}
\hline انحر اف استاندارد & ميانخين & & متغير \\
\hline $1 / \cdot r$ & $r / 90$ & & استرس شغلى \\
\hline$r / 4 F$ & $1 \cdot 101$ & & تعارض كار - خانواده \\
\hline $1 / \cdot 0$ & T/VI & شوق به كار & اشتياق شغلى \\
\hline$\cdot / \mathrm{AV}$ & T/AY & وقف شدن به كار & \\
\hline$\cdot / \wedge \Delta$ & $T / V V$ & جذبه در كار & \\
\hline$\cdot / 19$ & $T / V Y$ & اشتياق شغلى & \\
\hline
\end{tabular}


جدول r: همبستكى استرس شغلى و تعارض كار - خانو اده با اثتياق شغلى و ابعاد آن

\begin{tabular}{|c|c|c|c|c|}
\hline \multicolumn{2}{|c|}{ تعارض كار - خانواده } & \multicolumn{2}{|c|}{ استرس شغلى } & \multirow[t]{2}{*}{ متغير } \\
\hline معنادارى & همبستخى & معنادارى & همبستخى & \\
\hline$\% \cdots$ & $-\cdot / \Delta Y^{* * *}$ & $\% \cdots \wedge$ & $-\cdot / \mu k \cdot{ }^{*}$ & اشتياق شغلى \\
\hline.$\cdots$ & $-\cdot / 49 V^{* * *}$ & $\cdot / \cdots$ & $-\cdot / \Gamma 4 Q^{* * * *}$ & شوق داشتن به كار \\
\hline$\bullet$ &.$- / 499^{* * *}$ & 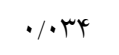 & $-\cdot / T V Y^{*}$ & وقف شدن به كار \\
\hline$\cdot / \cdots$ & -・MYYI & $\cdot / \cdots$ & 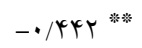 & جذبه در كار \\
\hline
\end{tabular}

\begin{tabular}{|c|c|c|c|c|}
\hline \multirow[t]{2}{*}{ Sig } & \multirow[t]{2}{*}{$\bar{T}$} & \multirow{2}{*}{ ضرايب استاندارد } & ضرايب غير استاندارد & \multirow[t]{2}{*}{ مدل } \\
\hline & & & Std.E & \\
\hline$\% \cdots$ & $11 / 14 \lambda$ & & $4 / 994$ & ا ع عدد ثابت \\
\hline$\cdot / \cdot r$ & $-1 / 4 \wedge \Lambda$ & $-\cdot / \mathrm{Vr}$ &.$- / 10$ & استرس شغلى \\
\hline$\cdot / \cdots$ & $-4 / 119$ & $-\cdot / \uparrow \wedge$ &.$- / 1 V Q$ & تعارض كار - خانو اده \\
\hline
\end{tabular}

اين فرضيه كه (ابين تعارض كار - خانو اده با اشتياق شغلى برسـتاران

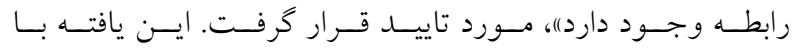

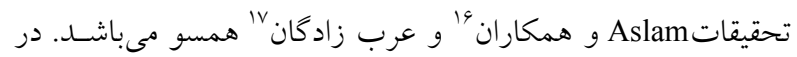
واقع از آنجا كه در فرآيند تعارض كـار-خـانواده نـوعى تعـارض و و تضاد نقش وجود دارد كـه ناشسى از ناسـازگارىهـاى موجــود بـين

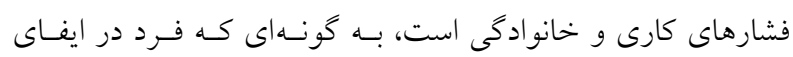

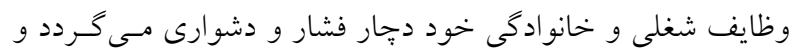
نمى تواند از عهلده الزامات هر دو نقش برآيد.

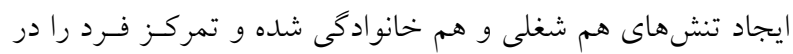

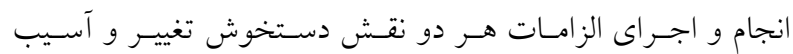
مى كند. در جنين حالتى وقتى كه فرد نتواند بر هيج يـك از تكـاليف

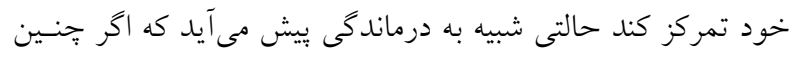
شرايطى تداوم يابد مىتواند منجر به درماندكى آموخته شــده شـودي.

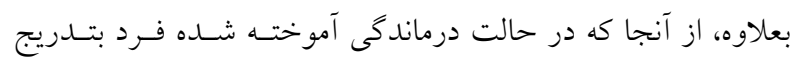
مىآموزد كه نقشى در تغيير شرايط ندارد و نمىتواند شرايط را تغيير الجها

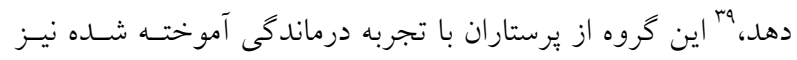

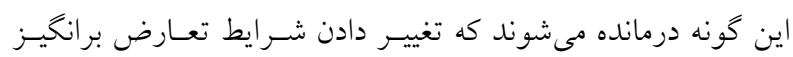
ايجاد شدهِ بين شغل و خانو اده براى آنان ممكن نيست و آنـان قـادر به بهبود شرايط نخواهند بود. اين ناتوانى در تغييـر و بهبـود شـرايط

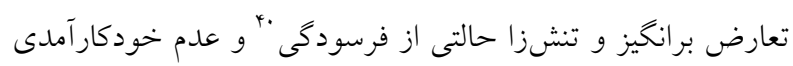

براساس جدول rا، بين استرس شغلى و تعارض كار - خانواده با اشتياق شغلى بصورت منفى و در سطحى معنادار همبسـتخى وجــود

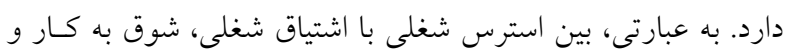
جذبه در كار (1 (•>p) و وقف شدن به كار رابطه منفى و معنادارى

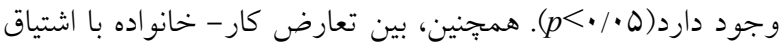

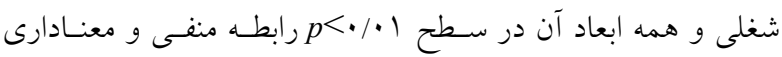
وجود دارد. بنابر اين، همه فرضيههاى مطرح شده در بالا مورد تاييـد قرار مى كيرد.

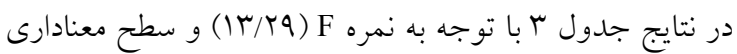

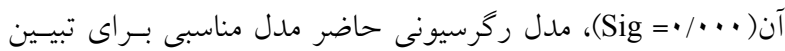

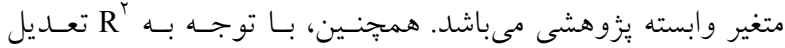

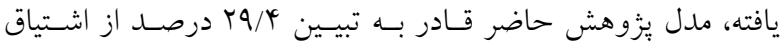

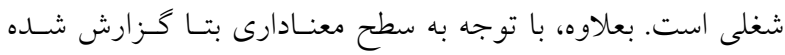
بــراى هــر دو متغيـر اسـترس شــلى و تعــارض كـار - خــانواده

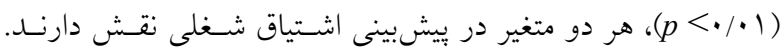
بنابراين، فرضيهى بالا مورد تاييد قرار مى گيرد.

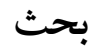

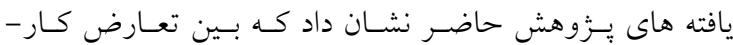
خانو اده با اشتياق شغلى رابطه منفى معنادارى وجـود دارد. بنـابراين 
فرسودكى شغلى (يعنى ياسخى به استرس طولانى مـــت مـرتبط بـا

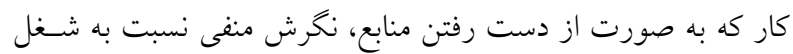

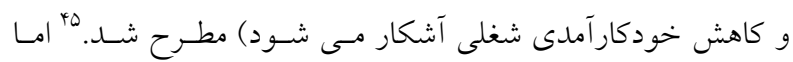

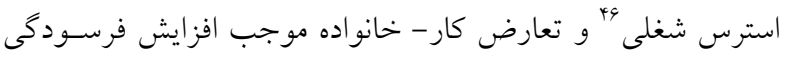

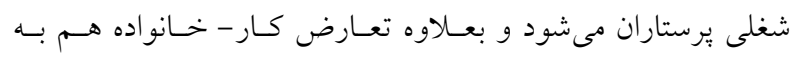

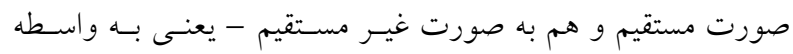

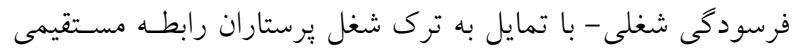

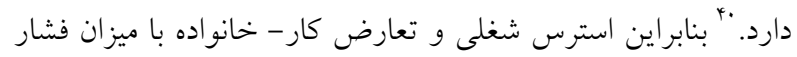

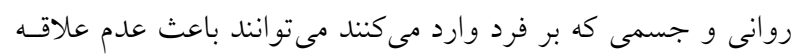
و رغبت يرستاران نسبت به شغلشان بشود. به عنوان مثال Lambert روتئ و Hogan فرسودگى شغلى بررسى كردند و يافتهها نشان داد كه تعارض كـار -

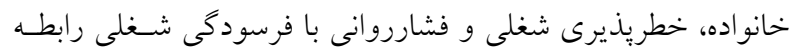

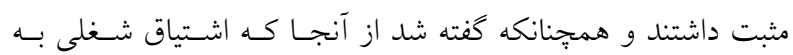

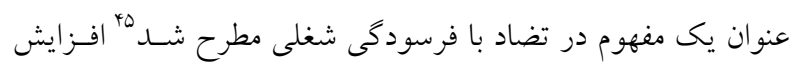

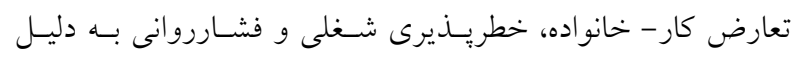

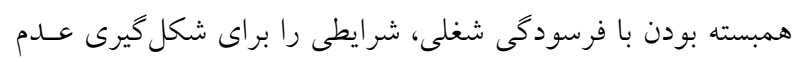
اشتياق به كار برستاران فراهمآورد.

\section{نتيجه گيرى}

در مجموع مىتوان كفت كه با در نظر كرفتن ميزان تعارض كار - خانو اده و سطح استرس شغلى كه يرستاران تجربه مى كنند امكـان

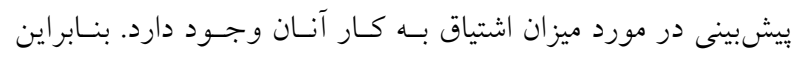

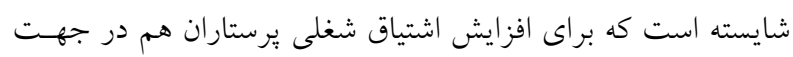

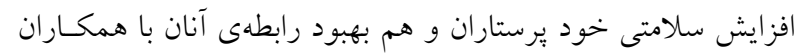

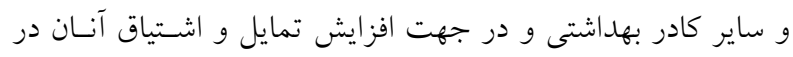

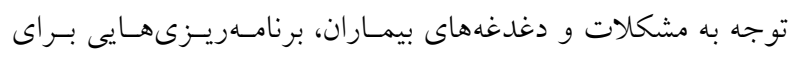

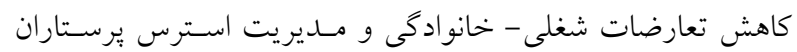

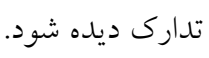

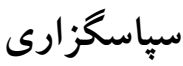

از كليـه كاركنـان و برسـتار ان شهرسـتان كُجسـاران كـه كمـال همكارى را در اجراى يُزوهش داشتند، تشكر مى شود.
را در فرد شكل مىدهد كه باعث مىشود فـرد از انجـام مشـتاقانهى

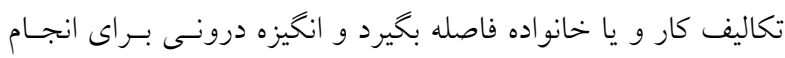

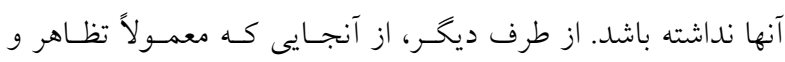

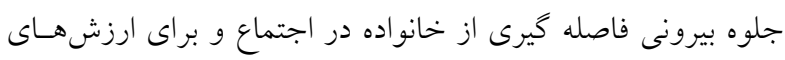
درونى شده خود فرد ناشايستهتر و ناساز گارانهتر اسـت تـا فاصـله

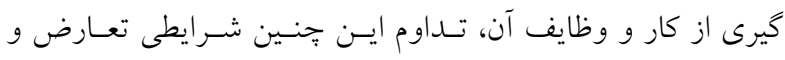
تضادى معمولا به زيان نقش كارى و شغلى يرسـتار مسى شـود و در نهايت باعث كاهش يافتن اشتياق و رغبت كارى فرد مى گردد. زيـرا

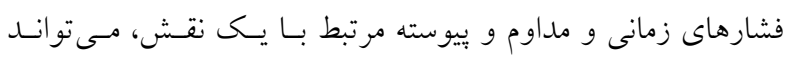

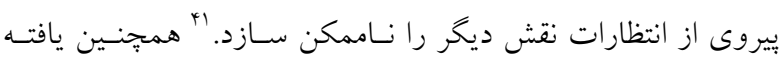

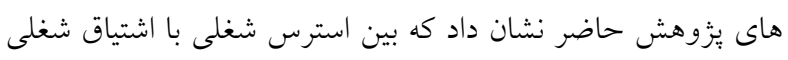

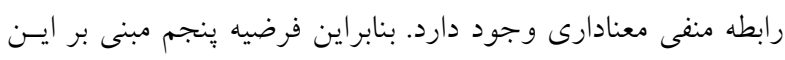

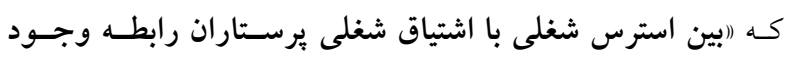

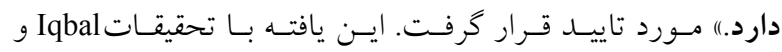

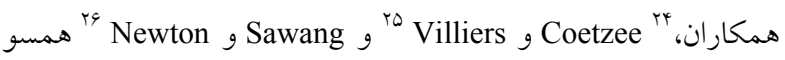

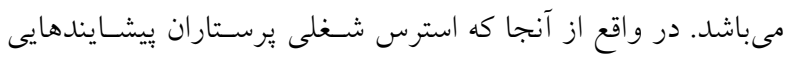

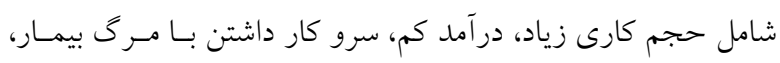
ارتباطات ضعيف با همكاران، ماهيت غير قابل ييش بينى شـغل، كـار شيفتى، آمادگى ناكافى، فقدان حمايتهاى روانى، تضاد با يزشـكان،

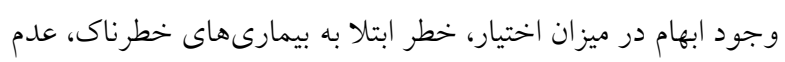

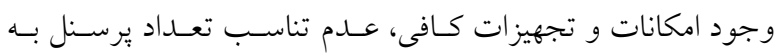

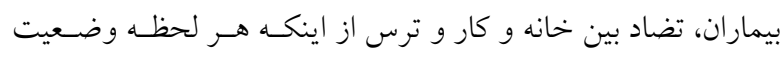

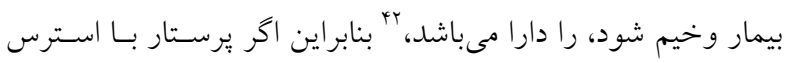

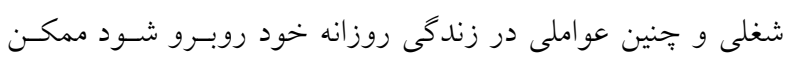

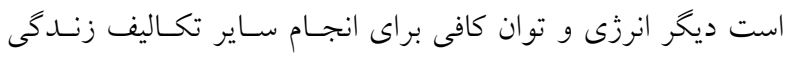

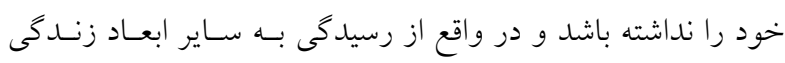
خود باز بماند. اين عدم توانايى و نداشتن انرزى و نيروى مورد نياز

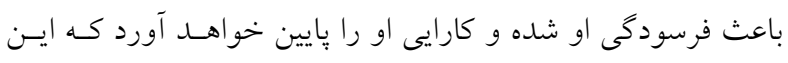

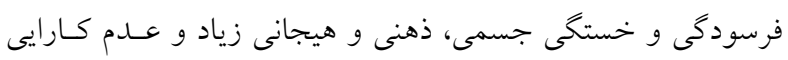

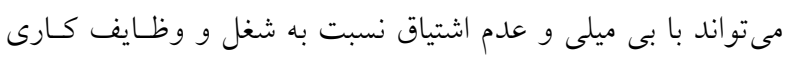

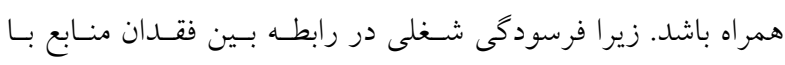

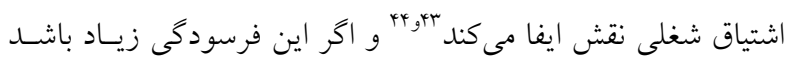

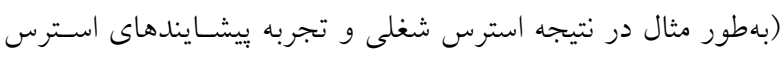
شغلى)، رابطه منفى بين فقدان منابع و استرس شغلى ناساز كارانهتـر

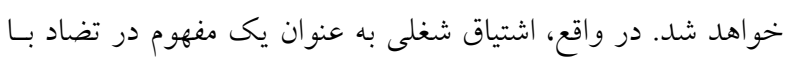




\section{References}

1. Pouraboli B, esfandiari S, Ramezani T, Miri S, Jahani Y, Sohrabi N. The efficacy of psychological empowerment skills to job stress in nursing staff in intensive care wards in center of Shahid Rajaee Hospital in Shiraz in 2013. Journal of Clinical Nursing and Midwifery 2016; 5(1): 23-35.

2. Salilih SZ, Abajobir AA. Work-related stress and associated factors among nurses working in public hospitals of Addis Ababa, Ethiopia: A CrossSectional Study. Workplace health \& safety 2014; 62(8):326.

3. Hashemi T, Golparvar M. The role of perceived organizational support on relationship of job stress and emotional exhaustion with turnover among nurses. Journal of Clinical Nursing and Midwifery 2015; 4(4): 29-39.

4. Schaufeli W. B, Salanova M, Gonzalez-Roma V, Bakker $\mathrm{AB}$. The measurement of burnout and engagement: A confirmatory factor analytic approach. Journal of Happiness Studies 2002; 3, 71-92.

5. Brunetto Y, Xerri M, Shriberg A, Farr-Wharton R, Shacklock K, Newman S, et al. The impact of workplace relationships on engagement, well-being, commitment and turnover for nurses in Australia and the USA. Journal of Advanced Nursing 2013; 69(12):2786-99.

6. Thian JHM, Kannusamy P, Klainin-Yobas P. Stress, positive affectivity, and work engagement among nurses: An integrative literature review. Singapore Nursing Journal 2013; 40(1):24-33.

7. Bakker, A. B., Tims, M., \& Derks, D. The development and validation of the job crafting scale. Journal of Vocational Behavior 2012; 80, 173 - 186.

8. Zargaran Mogadam S. The effects of job demands and Resources on burnout and work engagement of employees (Case Study: Isfahan Mobarakeh Steel Complex) Master Thesis, University of Isfahan, 2012.[In Persian]

9. Mache S, Bernburg M, Groneberg DA, Klapp BF, Danzer G. Work family conflict in its relations to perceived working situation and work engagement. Work. 2016(Preprint):1-11.

10. Leineweber C, Chungkham HS, Westerlund H, Tishelman C, Lindqvist R. Hospital organizational factors influence work-family conflict in registered nurses: Multilevel modeling of a nation-wide cross-sectional survey in Sweden. International journal of nursing studies 2014; 51(5):744-51.

11. Unruh LY, Raffenaud A, Fottler M. Work-Family Conflict among Newly Licensed Registered Nurses: A Structural Equation Model of Antecedents and Outcomes. Journal of healthcare management/American College of Healthcare Executives 2015; 61(2):129-45.

12. Mazerolle, S. M., Bruening, J. E., \& Casa, D. J. Workfamily conflict, Part II: Job and life satisfaction in national collegiate athletic association division I-A certified athletic trainers Journal of Athletic Training 2008; 43(5), 505-12.

13. Chen IH, Brown R, Bowers BJ, Chang WY. Work-to-family conflict as a mediator of the relationship between job satisfaction and turnover intention. Journal of advanced nursing 2015; 71(10):2350-63.

14. Wayne JH, Casper WJ, Matthews RA, Allen TD. Familysupportive organization perceptions and organizational commitment: The mediating role of work-family conflict and enrichment and partner attitudes. Journal of Applied Psychology 2013; 98(4):606.

15. Lambert EG, Minor KI, Wells JB, Hogan NL. Leave Your Job at Work The Possible Antecedents of WorkFamily Conflict Among Correctional Staff. The Prison Journal 2015; 95(1):114-34.

16. Aslam, R., Shumaila, S., Azhar, M., \& Sadaqat, S. Workfamily conflicts: Relationship between work-life conflict and employee retention: A comparative study of public and private sector employees interdisciplinary. Journal of Research in Business 2011; 1(2), 18-29.

17. Arabzadegan M. The relationship between work engagement with staff work-family conflict and mental health with the mediating role of Supervisor protection and family support in Isfahan Oil Refining Company staff. Theses MA Industrial and Organizational Psychology, Faculty of Psychology and Educational Sciences, Isfahan University, 2012.[In Persian]

18. Pirhayaie S, Nisi A, Neami A. The relationship between work-family conflict and family work with passion and desire to stay in a job on the staff of a petrochemical company in Mahshahr. New findings in psychology, 2013; 7 (23), 114-95.

19. Yekta S. The nature and importance of organizational behavior in nurse - Mental Stress and job stress in the organization. National Conference of organizational behavior in nursing, Shirvan, Shirvan Islamic Azad University, 2012; http://www.civilica.com/PaperNCQBN01-NCQBN01 046.htm

20. Al-khasawneh AL, Moh S. The relationship between job stress and nurses performance in the Jordanian hospitals: A case study in King Abdullah the Founder Hospital. Asian Journal of Business Management 2013; 5(2):26775 .

21. Lu, K., Chang, L., \& Wu, H. Relationships between Professional Commitment, Job Satisfaction, and work Stress in Public Health Nurses in Taiwan Journal of Professional Nursing 2007; 23(2), 110-116.

22. Karimi L, Leggat SG, Donohue L, Farrell G, Couper GE. Emotional rescue: The role of emotional intelligence and emotional labor on well-being and job-stress among community nurses. Journal of advanced nursing 2014; 70(1):176-86. 
23. Van Bogaert P, Adriaenssens J, Dilles T, Martens D, Van Rompaey B, Timmermans O. Impact of role-, job-and organizational characteristics on Nursing Unit Managers' work related stress and well-being. Journal of advanced nursing 2014; 70(11):2622-33.

24. Iqbal, T., Khan, K., \& Iqbal, N. Job stress \& employee engagement. European Journal of Social Sciences ISSN1, 2012; 28(1), 109-118.

25. Coetzee, M., \& Villiers, M. D. E. Sources of job stress, work engagement and career orientations of employees in a South African financial institution. Southern African Business Review 2010; 14(1), 57-27.

26. Sawang, S., \& Newton, J. C. Psychological stress and employee engagement. Publisher: Springer, Editors: Michalos, Alex C., 2014; pp.5161-5166

27. Hafezi far B, Eftekhr Z, Shojaie R. The relationship between work-family conflict and family work with passion and desire to stay in a job on the staff of a petrochemical company in Mahshahr. New findings in psychology 2012; 7 (23), 114-95.

28. Adib-Hajbaghery, M., Khamechian, M., \& Alavi, N. M. Nurses' perception of occupational stress and its influencing factors: A qualitative study. Iranian journal of nursing and midwifery research, 2012; 17(5), 352. [In Persian]

29. Delaware, A. Research Methods in Psychology and Educational Sciences. Thirty-eighth edition, Tehran edited publication, 2013.

30. Kabirzadeh, K, examines the relationship between customer satisfaction and enthusiasm for working with Maskan Bank Branches in Ilam province. Master's thesis, Islamic Azad University of Ilam; 2014.

31. Carlson, D. S., Kacmar, K. M., \& Williams, L. J. Construction and initial validation of a multidimensional measure of work-family conflict. Journal of Vocational Behavior 2000; 56, 249-276.

32. Watai, I., Nishikido, N., \& Murashima, S. Development of a Japanese Version of the Work-Family Conflict Scale (WFCS), and examination of its validity and reliability. Sangyo Eiseigaku Zasshi, 2006; 48(3), 71-81.

33. Motashari MH, Nisi A, Arshadi N. Test reliability and validity of work-family conflict and Kakmar Carlson and Williams. Journal of Industrial Psychology 2014; 4 (14), No. 14.

34. Gray-Toft, P., \& Anderson, J. G. The nursing stress scale: development of an instrument. Journal of Psychopathology and Behavioral Assessment 1981; 3, 11-23.

35. Cha, E-S., Kim, K. H., \& Erlen, J.A. Translation of scales in cross cultural research: issues and techniques. J Adv
Nurs 2007; 58:386-95.

36. Rezaee N, Behbahany N, Yarandy A, Hosseini F. Correlation between Occupational Stress and social support among Nurses. Iran Journal of Nursing 2006; 19(46), 71-78. [Persian]

37. Paghoush A, Zarei E, Damizadeh H, Sajjadi SE, Zeinalipour $H$. The Examination of the Causal Relationship between Work-Family Conflict and Burnout in Sarkhoon \& Qeshm Gas Treating. South journal of Educational Psychology and Counseling ISSN 24234915. 2015; 2(3).

38. Azura, A. The relationship between work-family conflict (WFC) and family- work conflict (FWC) towards job burnout: A case at sarawak economic development corporation (SEDC). Master's thesis, University Utara Malaysia.2006

39. Seligman ME, Csikszentmihalyi M. Positive psychology: An introduction: Springer; 2014.

40. Mohammadi Mahmuei, A. The impact of work-family conflict through burnout, on the willingness to leave the organization. Thesis Master public management human resources orientation, Faculty of Management and Hesabdray Allameh Tabatabai University, Tehran, 2013.[In Persian]

41. Tavangar H. Elany F, Vanaky Z. Coping strategies work / family conflict in Nurses: A Qualitative Study. Journal of Faculty of Nursing and Midwifery of Hamadan 2013; 20(1)

42. Teimurid F. Job stress factors among nurses. Journal Nursing college of Islamic Republic Army of Iran 2012; 11 (1), 35-32.

43. Spânu F, Baban A, Montgomery A, Panagopoulou E. Job Demands, Burnout, and Engagement Among Nurses: a Multilevel Analysis Investigating the Role of Teamwork. European Health Psychologist 2014; 16(S):296.

44. Hakanen, J. J., Bakker, A. B., \& Schaufeli, W. Burnout and work engagement among teachers. Journal of School Psychology 2006; 43, 495-513.

45. Hallberg, U. E. \& Schaufeli, W. B. "Same, same, but different"? Can work engagement be empirically separated from job involvement and organizational commitment? European Psychologist 2006; 11, 119-127.

46. Garcia,GRole stress and job engagement towards understanding positive psychology. MA. San Jose State University.2006.

47. Lambert, E. G., \& Hogan, N. L. Work-family conflict and job burnout among correctional staff. Psychological Reports Journal Impact Factor \& Description 2010; 106(1), 19-26. 